
\title{
25 Research Suare \\ Self-Reported Physical and Mental Health of Copd and Nsclc Caregivers: Relevance for Palliative Care Implementation in Serbia
}

\section{Dragana Maric}

University of Belgrade: Univerzitet u Beogradu

Dragana Jovanovic

University of Belgrade: Univerzitet u Beogradu

Ljudmila Nagorni Obradovic

University of Belgrade: Univerzitet u Beogradu

Tatjana Adzić Vukicevic

University of Belgrade: Univerzitet u Beogradu

Spasoje Popevic

University of Belgrade: Univerzitet u Beogradu

Tatjana Pekmezovic ( $\square$ pekmezovic@sezampro.rs )

Institute of Epidemiology,Faculty of Medicine, University of Belgrade https://orcid.org/0000-0001-

7978-1409

\section{Research Article}

Keywords: caregiver, quality of life, COPD, NSCLC

Posted Date: June 21st, 2021

DOl: https://doi.org/10.21203/rs.3.rs-563449/v1

License: (c) (1) This work is licensed under a Creative Commons Attribution 4.0 International License.

Read Full License 


\section{Abstract}

The purpose: In context of forthcoming implementation of palliative care in Serbia we aimed to evaluate and compare the quality of life (QoL) and depressive symptoms level of chronic obstructive pulmonary disease (COPD) and non-small cell lung cancer (NSCLC) caregivers and to analyze the impact of demographic and socioeconomic factors as well as the correlation of patients' quality of life with the quality of life of caregivers.

Methods: A cross-sectional survey of 200 caregivers and the patients they care for was undertaken in a three-year period. The Medical Outcomes 36-item Short Form Health Survey (SF-36) (Serbian version) was used to measure caregivers and patient's health-related quality of life and Standard 21-item Beck Depression Inventory (BDI) was given to each study participant (patient and caregiver) in order to explore feelings and attitudes relating to general depressive status. Data were analyzed using appropriate statistical methods.

Results of our study did not show a significant difference in most QoL domains and depressive symptoms of the two caregiver groups, but it did show a difference in the domain of general health (GH) and physical health (PHC) measured by the SF-36 ( $p=0.003$ and $p=0,038$, respectively) in COPD caregivers.

Conclusion: Particularly vulnerable caregiver group, the one that cared for patients with COPD, perceived their own general and physical health significantly worse compared to NSCLC caregivers. More depressed caregivers and those with a longer duration of unemployment (regardless of the disease type) reported poorer quality of life and represented a groups with greater support needs.

\section{Introduction}

Contemporary palliative care philosophy and the current definition of palliative care include all advanced life-threatening illnesses, of whatever diagnosis, rather than making sole reference to cancer [1]. It is an approach that improves the quality of life (QoL) of patients and their significant others facing the problems associated with life-threatening illness, placing at the center of such care patient-caregiver dyad as "palliative care unit"[2]. Until 2009, Serbia had no national guidelines, recommendations, standards or policy concerning palliative care. In 2009, the Ministry of Health published a National Palliative Care Strategy which presents a good foundation for the development of palliative care in Serbia [3].

Nevertheless, proposed different models for palliative care delivery have not yet fully emerged in medical practice and palliative approach (a set of skills expected of every health professional who provides care for someone with life-limiting illness) is not sufficiently present among physicians dedicated to the treatment of terminally ill patients. Therefore, family members provide most care for individuals who are living and dying with serious illnesses and are at the risk for impaired well-being, especially since specialized services for the provision of professional support them in their role does not exist. 
In everyday practice of respiratory medicine in Serbia, respiratory physicians spend much of their professional lives treating patients with COPD and lung cancer, usually in the same hospital setting and with the support of the same medical and nursing teams. Both diseases are among the top causes of death in Serbia and worldwide [4, 5]. Although lung cancer and COPD are characterized by different illness trajectories (short period of evident decline vs long term limitations with intermittent serious episodes) [6], both diseases are preceded by periods of declining health with many burdensome symptoms, communication issues and other unresolved palliative needs. The existing literature suggests that patients dying of chronic lung disease (including COPD) experience physical symptoms and psychosocial distress at least as severe as patients with lung cancer [7, 8]. Being a caregiver for an ill or disabled loved one is widely recognized as a threat to the caregiver's quality of life and mental health [9]. While many family caregivers wish to provide care, they often face considerable burden and distress [10], and are expected to take on increasing amounts of physical and emotional care for individuals with lifethreatening and terminal illnesses.

The solidarity emerged in patient-caregiver relationship during end-of-life care may be manifested by similar psychological responses and attitudes. In this regard, several studies have suggested the association between patients' and caregivers' mental health $[11,12]$. On the other hand, it seems that despite the different illness trajectories (of advanced life-threatening illnesses), diagnosis is not crucial to the quality of life, burden and mental health of caregivers $[13,14]$.

For the future development of caregivers' support strategy and increasing awareness of caregiving in Serbia, the aim of this study was to evaluate and compare the quality of life and depressive symptoms level of COPD and NSCLC caregivers and to analyze the impact of demographic and socioeconomic factors as well as the correlation of patients' quality of life with the quality of life of caregivers.

\section{Methods}

A cross-sectional survey of caregivers and the patients they care for was undertaken between January 2010 and June 2013 at the Clinic of Pulmonology, Clinical Center of Serbia, Belgrade, which is a university hospital and a public tertiary care facility. In our country everyone has full health insurance coverage and access to care is equal.

Two hundred informal caregivers were approached through the patient. The recruitment data of 100 patients with advanced (stage IIIb, IV) NSCLC [15] and 100 patients with stage IV of COPD [16], together with their clinical data (demografic, socioeconomic and QoL data), were published elsewhere [17]. A family caregivers were defined as "individuals who provide any phisical, emotional, and instrumental support and assistance to individuals with life-limiting illness that they view as family members. These family caregivers are not acting in profesional or occupational capacity. They may or may not be coresiding with the care recipient and the care recipient may be in either a home or institutional setting" [10]. Exlusion criteria were: age less than 18 years, presense of severe cognitive deficiency and refusal of the caregiver to participate in the study. 
Demographic and socio-economic data were obtained directly from caregivers and patients during the interviews. Items included gender, current age, mean age at the beginning of disease, type of relationship, caring duration, place of residence, occupation, education, employment status, unemployment duration, earning, homeownership, car-ownership, marital status, number of household members, number of children, religion, nationality, presence and number of comorbidities, knowledge of the diagnosis and prognosis.

The Medical Outcomes 36-item Short Form Health Survey (SF-36) (Serbian version) was used to measure caregivers and patient's health-related quality of life. The SF-36 is generic health survey questionnaire and comprises eight subscales: Physical Functioning (PF), Role Physical (RP), Bodily Pain (BP), General Health (GH), Vitality (VT), Social Functioning (SF), Role Emotional (RE) and Mental Health (MH). Based on these eight scales, two summary scales have been constructed: the Physical Component Summary (PCS) and the Mental Component Summary (MCS). Higher scores of SF-36 scales mean better quality of life [18].

Standard 21-item Beck Depression Inventory (BDI) was given to each study participant (patient and caregiver) in order to explore feelings and attitudes relating to general depressive status. Suggested cutoff values were: 0-10 no depression; 11-17: existence of mild depression: 18-23: moderate depression and 24+: severe depression [19].

Both instruments (SF-36 and BDI) were offered to both groups of patients and their caregivers by their attending physicians who were available for questions and explanations. Assistance was also provided if the patients was not capable of filling in the questionnaires because of vision problems, motor problems or fatigue.

Approval was obtained from the Ethics committee of Belgrade University. Informed consent was obtained from all participants.

\section{Statistical analysis}

Descriptive statistics were performed to examine descriptive variables for both patients and caregiver subjects. Simple linear regression was used to determine the impact of patients and caregiver's characteristics on caregivers QOL and depression. Variables significant at $p \leq 0.05$ in the simple regression analyses were included in the multiple regression model in order to identify factors that were independently associated with caregivers' QOL and depression. Analyses were performed using SPSS version 17.0. The study was previously approved by the Ethics Committee of the Faculty of Medicine, University in Belgrade.

\section{Results}


Study included 100 NSCLC and 100 COPD dyads (patients and their caregivers) who fulfilled inclusion criteria. There were 26 refusals, reasons to which included: patient refused without specific reason $=17$; patient too distressed / too unwell to participate $=6$; caregiver refused without specific reason $=3$.

Results related to socio-demographic characteristics, quality of life and depressive symptoms of NSCLC and COPD patients were published elsewhere [17].

The demographic and socio-economic characteristics of the two groups of caregivers are shown in Table 1. There was no statistically significant difference between the two groups of the caregivers according to their main demographic and socio-economic characteristics. The gender distribution for study participants was predominantly females $(n=70 ; 60)$. The majority of caregivers were in the role of spouse/partner followed by sons and daughter. Most caregivers were married, unemployed (in more than half) with low education level ( $\leq 12$ years of education). The COPD caregivers were significantly younger than NSCLC caregivers at the beginning of patients' disease, and caring duration was significantly longer among COPD caregivers, given the differences in the natural history and duration of the two diseases. Unemployment duration was significantly longer in group of NSCLC caregivers (12.54 vs 6.11 years) and car-ownership was more frequent among COPD caregivers. Although most of the caregivers in both groups were Orthodox Christians, other religions were more frequent in the group of COPD caregivers. Presence of comorbidities did not differ between the two groups, but the number of comorbidities was significantly higher in the COPD caregiver group. All 100 patients with COPD and 80 patients with NSCLC (and their caregivers) were available to assess the knowledge of diagnosis and prognosis of the disease. A significantly higher percent of COPD caregivers did not have knowledge about the diagnosis and prognosis compared to NSCLC caregivers. 
Table 1

Socio-demographic characteristics of two caregiver groups

\begin{tabular}{|c|c|c|c|}
\hline & $\begin{array}{l}\text { Caregivers - } \\
\text { LC }\end{array}$ & $\begin{array}{l}\text { Caregivers - } \\
\text { COPD }\end{array}$ & $\begin{array}{l}p- \\
\text { Value }\end{array}$ \\
\hline Gender & 30 & 40 & 0.138 \\
\hline Male & 70 & 60 & \\
\hline \multicolumn{4}{|l|}{ Female } \\
\hline Current age & $\begin{array}{l}52.17( \pm 12 . \\
75)\end{array}$ & $61.62( \pm 14.26)$ & 0.774 \\
\hline Mean age at the beginning of disease & $\begin{array}{l}51.92( \pm \\
12.70)\end{array}$ & $42.15( \pm 14.72)$ & 0.001 \\
\hline Type of relationship & 61 & 47 & 0,339 \\
\hline Spouse & 4 & 8 & \\
\hline Sister/brother & 30 & 38 & \\
\hline Daughter/son & 1 & 2 & \\
\hline Mother/father & 4 & 5 & \\
\hline \multicolumn{4}{|l|}{ Other } \\
\hline Caring duration (years) & $0.47 *$ & 8.27 & 0.001 \\
\hline Place of residence & 22 & 22 & 1.000 \\
\hline Rural & 78 & 78 & \\
\hline \multicolumn{4}{|l|}{ Urban } \\
\hline Occupation & 2 & 0 & 0.167 \\
\hline Farmers & 32 & 38 & \\
\hline Workers & 9 & 16 & \\
\hline Housewives & 31 & 30 & \\
\hline Clerks & $26^{*}$ & 16 & \\
\hline \multicolumn{4}{|l|}{ Experts } \\
\hline Education (number of years) & 27 & 29 & 0.335 \\
\hline$\leq 10$ & 43 & 50 & \\
\hline $10-12$ & 30 & 21 & \\
\hline$>12$ & & & \\
\hline
\end{tabular}




\begin{tabular}{|c|c|c|c|}
\hline & $\begin{array}{l}\text { Caregivers - } \\
\text { LC }\end{array}$ & $\begin{array}{l}\text { Caregivers - } \\
\text { COPD }\end{array}$ & $p_{\text {- }}$ Value \\
\hline Employment status & 43 & 38 & 0.471 \\
\hline Employed & 57 & 62 & \\
\hline \multicolumn{4}{|l|}{ Unemployed } \\
\hline Unemployment duration (years) & $\begin{array}{l}12.54( \pm \\
11.38)\end{array}$ & $6.11( \pm 8.29)$ & 0.001 \\
\hline Wage-earning & 53 & 46 & 0.322 \\
\hline Yes & 47 & 54 & \\
\hline \multicolumn{4}{|l|}{ No } \\
\hline Home-ownership & 81 & 80 & 0.858 \\
\hline Yes & 19 & 20 & \\
\hline \multicolumn{4}{|l|}{ No } \\
\hline Car-ownership & 69 & 50 & 0.006 \\
\hline Yes & 31 & 50 & \\
\hline \multicolumn{4}{|l|}{ No } \\
\hline Economic category & 61 & 45 & 0.076 \\
\hline 1. home and car & 28 & 40 & \\
\hline 2. home or car & 11 & 15 & \\
\hline \multicolumn{4}{|l|}{ 3. no home, no car } \\
\hline Marital status & 86 & 82 & 0.440 \\
\hline $\begin{array}{l}\text { Married/cohabiting } \\
\text { Single/divorced/separated/widowed }\end{array}$ & 14 & 18 & \\
\hline Number of household members & $3.35( \pm 1.68)$ & $3.30( \pm 1.51)$ & 0.825 \\
\hline Number of children & $1.46( \pm 0.915)$ & $1.38( \pm 1.13)$ & 0.584 \\
\hline Religion & 95 & 85 & 0.018 \\
\hline Orthodox Christian & 5 & 15 & \\
\hline \multicolumn{4}{|l|}{ Other } \\
\hline Nationality & 98 & 92 & 0.052 \\
\hline Serbian & 2 & 8 & \\
\hline Other & & & \\
\hline
\end{tabular}




\begin{tabular}{|llll|}
\hline & Caregivers - & Caregivers - & $\begin{array}{c}\text { P- } \\
\text { COPD }\end{array}$ \\
\hline Comorbidity & 48 & 48 & 1.000 \\
Yes & 52 & 52 & \\
\hline No & & & \\
\hline Knowledge of the diagnosis & $1.46( \pm 0.65)$ & $1.83( \pm 1.04)$ & 0.037 \\
Yes & $78(97.5 \%)$ & $72(72.0 \%)$ & 0.001 \\
No & $1(1.3 \%)$ & $17(17.0 \%)$ & \\
Not sure & $1(1.3 \%)$ & $11(11.0 \%)$ & \\
\hline Knowledge of the prognosis & & & 0.017 \\
Yes & $52(65.0 \%)$ & $45(45.0 \%)$ & \\
No & $8(10.0 \%)$ & $22(22.0 \%)$ & \\
Not sure & $20(25.0 \%)$ & $33(33.0 \%)$ & \\
\hline
\end{tabular}

The quality-of-life scores of the two caregiver groups are shown in Table 2. Although in our study [17], patients with COPD showed statistically significant lower QoL in all domains measured by the SF-36 questionnaire compared to patients with LC (except in the domain bodily pain), no such difference was observed in their caregivers. No significant difference was found in most SF-36 scores except for GH and PCS scales. However, the scores for GH and PSC differed significantly $(p=0.003 ; p=0.038)$, with COPD caregivers showing lower scores and poorer quality of life in these domains. 
Table 2

Quality of life measurements of two caregiver groups

\begin{tabular}{|c|c|c|c|c|c|}
\hline \multirow[t]{2}{*}{ Measurement } & \multicolumn{2}{|c|}{ Caregivers - LC } & \multicolumn{2}{|c|}{ Caregivers-COPD } & \multirow[t]{2}{*}{$p$-Value } \\
\hline & Mean (SD) & Min-Max & Mean (SD) & Min-Max & \\
\hline Physical functioning (PF) & $\begin{array}{l}85.40 \\
(19.73)\end{array}$ & $20-100$ & $80.3(26.98)$ & $0-100$ & 0.129 \\
\hline Role-physical (RF) & $\begin{array}{l}36.87 \\
(20.44)\end{array}$ & $0-50$ & $\begin{array}{l}33.87 \\
(21.56)\end{array}$ & $0-50$ & 0.314 \\
\hline Role-emotional (RE) & $\begin{array}{l}20.67 \\
(22.61)\end{array}$ & $0-50$ & $19.5(20.66)$ & $0-50$ & 0.704 \\
\hline Energy (VT) & $\begin{array}{l}55.55 \\
(25.01)\end{array}$ & $0-100$ & $50.7(24.3)$ & $0-95$ & 0.166 \\
\hline $\begin{array}{l}\text { Emotional wellbeing } \\
(\mathrm{MH})\end{array}$ & $\begin{array}{l}57.04 \\
(22.54)\end{array}$ & $0-100$ & $\begin{array}{l}56.92 \\
(20.91)\end{array}$ & $8-96$ & 0.969 \\
\hline Social functioning (SF) & $\begin{array}{l}55.68 \\
(31.59)\end{array}$ & $0-100$ & $\begin{array}{l}56.37 \\
(29.33)\end{array}$ & $0-100$ & 0.873 \\
\hline Bodily pain (BP) & $\begin{array}{l}81.52 \\
(24.19)\end{array}$ & $10-100$ & $\begin{array}{l}75.97 \\
(27.56)\end{array}$ & $0-100$ & 0.132 \\
\hline General health (GH) & $\begin{array}{l}63.10 \\
(19.00)\end{array}$ & $25-100$ & $\begin{array}{l}54.37 \\
(22.56)\end{array}$ & $10-100$ & 0.003 \\
\hline $\mathrm{PHC}$ & $\begin{array}{l}66.72 \\
(16.80)\end{array}$ & $\begin{array}{l}26.25- \\
87.50\end{array}$ & $61.13(20.9)$ & $3.75-87.5$ & 0.038 \\
\hline $\mathrm{MHC}$ & $\begin{array}{l}47.23 \\
(20.43)\end{array}$ & $0-87.50$ & $\begin{array}{l}45.97 \\
(19.95)\end{array}$ & $4-82$ & 0.634 \\
\hline TOTAL & $\begin{array}{l}56.98 \\
(16.20)\end{array}$ & $13.13-87.5$ & $53.5(18.0)$ & $\begin{array}{l}3.88- \\
83.38\end{array}$ & 0.153 \\
\hline Beck (BDI) & $9.87(7.82)$ & $0-45$ & $12.01(9.12)$ & $0-38$ & 0.076 \\
\hline
\end{tabular}

The highest scores in both caregiver groups (NSCLC and COPD) were achieved on the PF scale (85.40 (19.73); 80.3 (26.98), respectively) and the lowest on the RE scale (20.67 (22.61); 19.5 (20.66)). Thus, the most vulnerable domain of caregivers' QoL was emotional functioning.

Results of the simple and multiple regression analyses examining caregiver factors as well as patients' QoL (PCS, MCS) and depression related to caregivers' QoL (SF-36 PCS) for both diseases are presented in Table 3. Simple regression analysis found statistically significant associations between NSCLC caregivers PCS and gender, current age, type of relationship, mean age at the onset of disease, employment status, working, home-and car-ownership, presence of comorbidity and BDI score; between COPD caregivers PCS and current age, mean age at the beginning of disease, employment status, unemployment duration, working, car-ownership, presence of comorbidity, knowledge of prognosis and 
BDI score. Multiple regression analysis found that factors independently associated with (worse) NSCLC caregivers PCS were older age at the beginning of disease and BDI score. Two independent variables were significantly associated with COPD caregivers (worse) PCS - presence of comorbidity and BDI score. Quality of life of NSCLC and COPD patients did not show influence on caregivers' physical QoL. 
Table 3

Caregiver variables and patients' QoL associated with caregivers' QoL (SF-36 PCS)

\begin{tabular}{|c|c|c|c|c|c|c|}
\hline & \multicolumn{3}{|c|}{ Simple regression analysis } & \multicolumn{3}{|c|}{ Multiple regression analysis } \\
\hline & B & SE & $\mathbf{P}$ & $\beta$ & SE & $\mathbf{p}$ \\
\hline \multicolumn{7}{|l|}{ NSCLC } \\
\hline \multicolumn{7}{|l|}{ Caregiver variables } \\
\hline Gender & -7.833 & 3.599 & 0.032 & & & \\
\hline Current age & -0.554 & 0.121 & 0.001 & & & \\
\hline Type of relationship & 3.176 & 1.457 & 0.032 & & & \\
\hline Mean age at the beginning of disease & -0.562 & 0.121 & 0.000 & -0.446 & 0.114 & 0.001 \\
\hline Employment status & -8.551 & 3.300 & 0.011 & & & \\
\hline Earning & -10.079 & 3.227 & 0.002 & & & \\
\hline Home-ownership & 9.769 & 4.190 & 0.022 & & & \\
\hline Comorbidity & 11.656 & 3.168 & 0.001 & & & \\
\hline Beck (BDI) & -0.984 & 0.193 & 0.000 & -0.817 & 0.185 & 0.001 \\
\hline \multicolumn{7}{|l|}{ Patients'QoL } \\
\hline SF-36 PCS & -0.013 & 0.092 & 0,890 & & & \\
\hline SF-36 MCS & 0.108 & 0.089 & 0.227 & & & \\
\hline Beck (BDI) & 0.289 & 0.238 & 0.228 & & & \\
\hline \multicolumn{7}{|l|}{ COPD } \\
\hline \multicolumn{7}{|l|}{ Caregiver variables } \\
\hline Current age & -0.384 & 0.143 & 0.009 & & & \\
\hline Mean age at the beginning of disease & -0.328 & 0.139 & 0.021 & & & \\
\hline Employment status & -8.441 & 4.243 & 0.049 & & & \\
\hline Unemployment duration & -0.819 & 0.344 & 0.021 & & & \\
\hline Earning & -10.384 & 4.082 & 0.013 & & & \\
\hline Car-ownership & -11.188 & 4.046 & 0.007 & & & \\
\hline Comorbidity & 9.061 & 4.104 & 0.030 & 10.681 & 4.834 & 0.031 \\
\hline Beck (BDI) & -1.406 & 0.183 & 0.001 & -1.375 & 0.276 & 0.001 \\
\hline
\end{tabular}




\begin{tabular}{|c|c|c|c|c|c|c|}
\hline & \multicolumn{3}{|c|}{ Simple regression analysis } & \multicolumn{3}{|c|}{ Multiple regression analysis } \\
\hline & B & SE & $\mathbf{P}$ & $\beta$ & SE & $\mathbf{p}$ \\
\hline SF-36 PCS & 0.294 & 0.212 & 0.172 & & & \\
\hline SF-36 MCS & -0.131 & 0.172 & 0.451 & & & \\
\hline Beck (BDI) & 0.394 & 0.337 & 0.248 & & & \\
\hline
\end{tabular}

Table 4 presents results of the simple and multiple regression analyses evaluating caregiver factors and patients' QoL (PCS, MCS) and depression, related to caregivers' QOL (SF-36, MCS) for both diseases. Simple regression analyses demonstrated statistically significant association between NSCLC caregivers MCS and gender, current age, age at onset of disease, unemployment duration and BDI score; between COPD caregivers MSC and current age, age at onset of disease, unemployment duration, car-ownership and BDI score. Multiple regression analyses established factors independently associated with (worse) caregivers' MCS (NSCLC and COPD): unemployment duration and BDI score. Quality of life of NSCLC and COPD patients did not show influence on caregivers' mental QoL (MCS). 
Table 4

Caregiver variables and patients' QoL associated with caregivers' QoL (SF-36 MCS)

\begin{tabular}{|c|c|c|c|c|c|c|}
\hline \multirow[t]{2}{*}{ Variable } & \multicolumn{3}{|c|}{ Simple regression analysis } & \multicolumn{3}{|c|}{ Multiple regression analysis } \\
\hline & B & SE & $\mathbf{P}$ & $\boldsymbol{\beta}$ & SE & $\mathbf{p}$ \\
\hline \multicolumn{7}{|l|}{ NSCLC } \\
\hline \multicolumn{7}{|l|}{ Caregiver variables } \\
\hline Gender & -14.785 & 4.224 & 0.001 & & & \\
\hline Current age & -0.333 & 0.158 & 0.038 & & & \\
\hline Mean age at the beginning of disease & -0.340 & 0.159 & 0.035 & & & \\
\hline Unemployment duration & -0.443 & 0.227 & 0.056 & -0.474 & 0.194 & 0.019 \\
\hline Comorbidity & 7.542 & 4.039 & 0.065 & & & \\
\hline Knowledge of diagnosis & -19.951 & 9.471 & 0.038 & & & \\
\hline Beck (BDI) & -2.070 & 0.161 & 0.001 & -1.882 & 0.219 & 0.001 \\
\hline \multicolumn{7}{|l|}{ Patients'QoL } \\
\hline SF-36 PCS & -0.010 & 0.081 & 0.900 & & & \\
\hline SF-36 MCS & 0.101 & 0.078 & 0.195 & & & \\
\hline Beck (BDI) & 0.100 & 0.208 & 0.630 & & & \\
\hline \multicolumn{7}{|l|}{ COPD } \\
\hline \multicolumn{7}{|l|}{ Caregiver variables } \\
\hline Current age & -0.292 & 0.138 & 0.037 & & & \\
\hline Mean age at the beginning of disease & -0.284 & 0.134 & 0.037 & & & \\
\hline Unemployment duration & -1.00 & 0.283 & 0.001 & -0.503 & 0.209 & 0.020 \\
\hline Car-ownership & -7.871 & 3.930 & 0.048 & & & \\
\hline Beck (BDI) & -1.605 & 0.150 & 0.001 & -1.518 & 0.199 & 0.001 \\
\hline \multicolumn{7}{|l|}{ Patients'QoL } \\
\hline SF-36 PCS & 0.168 & 0.151 & 0.270 & & & \\
\hline SF-36 MCS & -0.006 & 0.123 & 0.963 & & & \\
\hline Beck (BDI) & -0.002 & 0.240 & 0.994 & & & \\
\hline
\end{tabular}

Discussion 
Given the clear differences in the nature and course of two lung diseases (COPD and NSCLC), and the shown differences in the QoL between the two groups of our patients [17], where COPD patients demonstrated significantly worse QoL than NSCLC patients across all domains, there was an assumption that the quality of life of their caregivers will also differ. Especially having in mind the already welldemonstrated interdependence between informal caregivers and care recipients' QoL $[12,20]$.

Nevertheless, our study did not show a significant difference in most QoL domains and depressive symptoms of the two caregiver groups, but it did show a difference in the domain of general health (GH) and physical health (PHC) measured by the SF-36 ( $p=0.003$ and $p=0,038$, respectively). Thus, COPD caregivers perceived their own general and physical health as inferior to NSCLC caregivers. Self-rated physical (and mental) health is reported to be significantly worse in caregivers of people with advanced COPD when compared to those caring for people with early COPD [21,22] and all included patients in our study had advanced disease. Another possible explanation for poorer perception of general and physical health of COPD caregivers lies in the fact that there was a significant difference in the average number of comorbidities between the two caregiver groups - more comorbidities were observed in the group of COPD caregivers (NSCLC $-1.46 \pm 0.65$; COPD $-1.83 \pm 1.04 ; p=0.037$ ). Also, the average caring duration for COPD patients was 8.27 years, while for NSCLC it was slightly less than 5 months $(p=0.001)$, probably leading to deterioration of physical health of COPD caregivers over time. On the other hand, our results are in line with results of several other studies which also did not confirm the influence of the disease type on caregiver burden and QoL. It is already known that the patients' illness experience is more related to illness severity than the diagnosis of advanced disease [23] and all patients in our study sample (COPD and NSCLC) had advanced disease stage. Also, study comparing cancer, CHF and COPD caregivers found similar level of caregiver burden across different patient's diagnoses, suggesting that caregiver burden may not be disease-specific, rather a universal phenomenon of caring for adults with life-limiting diseases [14]. Similarly, study of 139 patient/caregiver dyads (51 living with cancer, 46 living with $\mathrm{CHF}$ and 42 living with COPD) demonstrated that diagnosis was not significantly associated with caregiver burden or psychosocial-spiritual outcomes in multivariate models. Authors concluded that caregiver burden is not disease specific, but it is rather a relatively universal experience [13].

Contrary to the results of our study, which did not show a relationship between the patients and the caregivers' QoL, numerous studies primarily in the oncology field, have shown the adverse impact of poor patients' QoL and depression on caregivers' QoL $[9,12,13,24]$. Negative impact of declining patients' QoL on caregivers' distress level and positive relation between patient and caregiver depression are especially prominent in patients with advanced NSCLC, highlighting the close association between patient and caregiver outcomes $[12,20,25,26]$. The relation between patients and caregivers' QoL and emotional status has not reported only for patients with cancer but also in other chronic diseases [27, 28]. Data in the literature regarding the impact of COPD patients' QoL on caregivers' QoL are somewhat scarcer. In a study by Pinto RA et al. the QoL of caregivers of COPD patients seems to be negatively associated with low PCS score of the patients measured by SF-36. Thus, the poorer physical health of patients with COPD showed a negative impact on the quality of life of caregivers [29]. On the other hand, patients and their caregivers may have different perceptions of the patient's symptoms and health status [30]. This 
discrepancy in perception can negatively affect the caregivers and patients' well-being [31]. In that case patients and family members who care for them do not have to show the interdependence of the same direction and detecting the mutual influence of quality of life can be a challenge. This may be one possible explanation for the results in our study that did not confirm the impact of patients' physical and mental health (QoL) on caregivers' QoL. Two other studies also reported not finding association between patients' QoL and caregivers' well-being $[32,33]$ underling the significance of caregiver-related factors.

In our investigation, caregiver-related factors, were most influential on their QoL in both the physical and mental domains for both caregiver groups. In the multivariate model, a higher level of depressive symptomatology in caregivers predicted a poorer QoL in both the physical and mental domains in both caregiver groups: NSCLC $(p=0.001 ; p=0.001)$ and COPD $(p=0.001 ; p=0.001)$. Interestingly, at the same time, the level of depression of the patients they care for, did not show an impact on caregivers' QoL, although their interdependence is well described $[11,20]$. Caregiver depression is a well-researched topic. The caregiving process is physically and emotionally demanding and creates a feeling of burden, loneliness and depression in some caregivers, and may be associated with decrease in their QoL and have significant impact on their health, regardless of the type of disease [13,34]. That is, psychological distress significantly determined the subjective perception of physical and mental health. On the other side, there are studies among informal caregivers that have concluded that helping behavior in a caring context promotes psychological wellbeing [35].

In addition to depression in our caregiver sample, in the multivariate model older age proved to be an independent predictor of poorer physical QoL in NSCLC caregivers $(p=0.001)$, and in COPD caregivers the presence of comorbidity predicted poorer physical QoL $(p=0.031)$. Both observations, that older and sicker caregivers who at the same time experiencing mental and emotional strain and have reported more problems in the area of physical health, are in line with the already known risk factors for caregivers' physical health [36]. Caregivers of patients with COPD in our study were a particularly vulnerable group since the presence of comorbid diseases predicted poorer physical health, and the care period was significantly longer -8.27 years versus only 6 months for NSCLC caregivers. They also were approximately 10 years older than NSCLC caregivers. Thus, the decline in the physical health of those caring for seriously ill patients intensifies with the caring duration and the progression of the disease [37].

Interestingly, in our research, the mental well-being of caregivers (MCS), in addition to depressive symptomatology, was also influenced by the duration of unemployment. Although the duration of unemployment of the NSCLC caregivers were significantly longer than of COPD caregivers $(12,54( \pm$ $11,38)$ vs $6,11( \pm 8,29)$ years), longer unemployment duration was shown to be independent predictive factor for worse mental functioning in both caregiver groups $(p=0.019 ; p=0.020$, respectively). Socioeconomic factors and especially employment status have complex impact on the caregiving experience and the previous literature shows very mixed results in this regard. From potential benefits when caregivers are employed (higher income levels with positive influence on physical and emotional health [38], buffering for dissatisfaction in one of the roles - higher level of satisfaction with diverse social interactions and consequently fewer negative psychological symptoms [39]) to significant disadvantages 
of being an employed caregiver (reduced work responsibilities, termination of employment in order to cope with caregiving responsibilities [40], the psychological strain due to the simultaneous performance of multiple roles [41].

The data on the impact of the employment status on the physical and mental health of NSCLC and COPD caregivers are very scanty. Still, our results can be interpreted in line with results of recent study of dementia caregivers Liu Y et al, where caregivers who were not employed experienced increasing role overload (subjective feelings of being overwhelmed by care-related responsibilities) over time. Especially because in underdeveloped countries, unemployment generally implies the existence of financial disadvantage, and the above-mentioned study demonstrated that greater financial strain was associated with higher levels of role overload in general. Authors concluded that changes in caregivers' employment status may have complex association with their feelings of stress over time [42]. Similarly, several studies of informal caregivers of adults with mental illness reported significant negative effects of unemployment on caregivers' mental health and QoL $[43,44]$.

This study has several limitations. Although, study included respectable number of caregiver-patient dyads, they are recruited in tertiary care centre which impedes generalization of our results to the whole community. The accessibility of health services to patients with advanced diseases and their caregivers in remote areas can be significantly restricted. The cross-sectional study design prevents assessment of changes in QoL over time, particularly considering the different illness trajectories and duration of caregiving experience. Hence, our results can be biased because significantly longer caregiving duration of COPD caregivers. Further, to assess the presence of depressive symptoms, we used BDI as a screening tool, not a diagnostic instrument, and the frequency of depressive disorders has not been precisely determined.

In underdeveloped countries providing organized support to informal caregivers is a challenge. The context of insufficiently available dedicated palliative care can significantly frame the burden placed on caregivers. In such circumstances, the task of providing support to informal caregivers of patients with chronic lung disease in advanced stage is often taken over by respiratory physicians. Unfortunately, this support provided by physicians is very limited and consultative in its nature. Therefore, for developing models of support is necessary to take into account the needs of different caregiver groups and on the other side also lack of well-organized palliative care. Our research identified as particularly vulnerable caregiver group the one that cared for patients with COPD, as COPD caregivers perceived their own general and physical health significantly worse compared to NSCLC caregivers. Also, more depressed caregivers and those with a longer duration of unemployment (regardless of the disease type) reported poorer quality of life and represented a groups with greater support needs. Since the type of disease is not an essential determinant of caregiver's quality of life, a caregiver support model should be developed within general practice and home-based care rather than as a component of specialized palliative care in secondary and tertiary care facilities, taking into account particularly vulnerable groups of informal caregivers. Bearing in mind that a recently published study demonstrated very different approaches to caregiving in three developed EU countries (France, Germany, Italy)[45], highlighting the need for future 
studies to explore the country-specific context of caregiving we believe that special attention should be paid to caregiving research in underdeveloped countries with still inadequately implemented palliative care.

\section{Declarations}

\section{Funding:}

Dragana Maric and Tatjana Pekmezovic are supported by the Ministry of Education, Science and Technological Development of the Republic of Serbia (grant no. 200110)

\section{Conflicts of interest/Competing interests:}

The authors have no any conflict of interest to declare.

\section{Availability of data and material:}

Authors make sure that all data and materials support published claims and comply with field standards.

\section{Code availability:}

Authors make sure that software application and custom code support published claims and complies with field standards.

\section{Authors' contributions:}

DM gave substantial contributions to conception and design, acquisition of data, drafting the article and approval of the final version for submission. DJ gave substantial contributions to conception and design and approval of the final version for submission. LJNO included in data acquisition and approval of the final version for submission. TAV included in data acquisition and approval of the final version for submission. SP included in data acquisition and approval of the final version for submission. TP gave substantial contributions to conception and design, analysis and interpretation of data, revising the manuscript critically for important intellectual content and approval of the final version for submission.

\section{Ethics approval:}

The study was previously approved by the Ethics Committee of the Faculty of Medicine, University in Belgrade. 


\section{Consent to participate:}

Informed consent was obtained from all individual participants included in the study.

\section{Consent for publication:}

$\mathrm{N} / \mathrm{A}$

\section{Acknowledgement:}

This investigation was supported by the Ministry of Education, Science and Technological Development of the Republic of Serbia (Grant No 175087).

\section{References}

1. Murtagh FEM, Preston M, Higginson I (2004) Patterns of dying: palliative care for non-malignant disease. Clin Med 4:39-44. https://doi.org/10.7861/clinmedicine.4-1-39

2. World Health Organization (2002) National cancer control programmes: policies and managerial guidelines, 2nd edn. World Health Organization, Geneva

3. Republic of Serbia. National Palliative Care Strategy (2009) Belgrade

4. Cancer incidence and mortality in Central Serbia (2009) Cancer Registry of Central Serbia, Report No 11, Belgrade 2011

5. Istraživanje zdravlja stanovnika Republike Srbije (2006) Finalni izveštaj. Ministartsvo zdravlja Republike Srbije. Beograd, 2007

6. Murray S, Kendall M, Boyd K, Sheikh A (2005) Illnes trajectories and palliative care. BMJ 330:10071011. https://doi.org/10.1136/bmj.330.7498.1007

7. Edmonds P, Karlsen S, Khan S, Addington-Hall J (2001) A comparsion of the palliative care needs of patients dying from chronic respiratory diseases and lung cancer. Palliat Med 25:287-295. https://doi.org/10.1191/026921601678320278

8. Gore JM, Brophy CJ, Greenstone MA (2000) How well do we care for patients with end stage chronic obstructive pulmonary disease (COPD)? A comparsion of palliative care and quality of life in COPD and lung cancer. Thorax 55:1000-1006. https://doi.org/10.1136/thorax.55.12.1000

9. Kim Y, Spillers RL (2010) Quality of life of family caregivers at 2 years after a relative's cancer diagnosis. Psycho-Oncology 19(4):431-440. https://doi.org/10.1002/pon.1576

10. Stajduhar KI, Funk L, Grande GE, Aoun S, Todd, Cj (2010) Part 1: Home-based Family Caregiving at the End of Life: A comprehensive review of published quantitative research (1998-2008). Palliat Med 24(6):573-593. https://doi.org/10.1177/0269216310371412 
11. Fleming DA, Sheppard VB, Mangan PA et al (2006) Caregiving at the end of life: Perceptions of health care quality and quality of life among patients and caregivers. J Pain Symptom Manage 5:407-420. https://doi.org/10.1016/j.jpainsymman.2005.09.002

12. Tan JY, Molassiotis A, Lloyd Williams, Yorke J (2018) Burden, emotional distress and quality of life among informal caregivers of lung cancer patients: an exploratory study. Eur J Cancer Care 27 (1). https://doi.org/10.1111/ecc.12691

13. Burton AM, Sautter JM, Tulsky JA et al (2012) Burden and well-being among diverse sample of cancer, congestive hart failure and chronic obstructive pulmonary disease caregivers. J Pain Symptom Manage 44:410-420. https://doi.org/10.1016/j.jpainsymman.2011.09.018

14. Gralo K, O'Leary JR, Van Ness PH, Fried TR (2010) Burden in caregivers of older adults with advanced illness. J Am Geriatr Soc 58:2315-2322. https://doi.org/10.1111/j.15325415.2010.03177.x

15. Edge SB, Compton CC (2010) The American Joint Committee on Cancer: the 7th edition of the AJCC cancer staging manual and the future of. TNM Ann Surg Oncol 17(6):1471-1474. https://doi.org/10.1245/s10434-010-0985-4

16. Global Initiative for Chronic Obstructive Disease. Global strategy for the diagnosis, management and prevention of chronic obstructive pulmonary disease (updated 2009) 2010; Available at: http://www.goldcopd.org/ (accessed 21 February 2010)

17. Maric D, Jovanovic D, Nagorni-Obradovic Lj, Stjepanovic M, Kisic-Tepavcevic D, Pekmezovic T (2015) Assessment of health-related quality of life in end-stage chronic obstructive pulmonary disease and non-small cell lung cancer patients in Serbia. Palliative Supportive Care 1:1-9. https://doi.org/10.1017/s1478951515000589

18. SF-36 Health Survey (Original Version) Language Recalls. Available at: http://www.qualitymetric.com. (retrieved 10 January 2007)

19. Beck AT, Beck RW (1972) Screening depressed patients in family practice: a rapid technique. Postgrad Med 52:81-85

20. Jacobs JM, Shaffer KM, Nipp RD et all (2017) Distress is interedependent in patients and caregivers with newly diagnosed incurable cancers. Ann Behav Med 51: 519-531. https://doi.org/10.1007/s12160-017-9875-3

21. Figueiredo D, Gabriel R, Jacome C, Cruz J, Marques A (2014) Caring for relatives with chronic obstructive pulmonary disease: how does the disease severity impact on family carers? Aging Ment Health 18:385-393. https://doi.org/10.1080/13607863.2013.837146

22. Simpson AC, Rocker GM (2008) Advanced chronic obstructive pulmonary disease: impact on informal caregivers. J Palliat Care 24:49-54

23. Steinhauser KE, Arnold RM, Olson MK et al (2011) Comparing three life-limiting disease: does diagnosis matter, or is sick. sick? J Pain Symprom Manage 42:331-341. https://doi.org/10.1016/j.jpainsymman.2010.11.006 
24. Wadhwa D, Burman D, Swami N, Rodin G, Lo C, Zimmerman C (2013) Quality of life and mental health in caregivers of outpatients with advanced cancer. Psycho-Oncology 22:403-410. https://doi.org/10.1002/pon.2104

25. Borges EL, Franceschini J, Costa LH et al (2017) Familiy caregiver burden: the burden of caring for lung cancer patients according to cancer stage and patients quality of life. Journal Brasileiro de Pneumologia 43:18-23. https://doi.org/10.1590/s1806-37562016000000177

26. Wood R, Taylor-Stokes G, Smith F, Chaib C (2019) The humanistic burden of advanced non-small lung cancer (NSCLC) in Europe: a real-world survey linking patient clinical factors to patient and caregiver burden. Qual Life Res 28:1849-1861. https://doi.org/10.1007/s11136-019-02152-6

27. Gotze H, Brahler E, Gansera L, Polze N, Kohler N (2014) Psychological distress and quality of life of palliative cancer patients and their caring relatives during home care. Support Care Cancer 22:27752782. https://doi.org/10.1007/s00520-014-2257-5

28. Chung ML, Lennie TA, Mudd-Martin G, Dunbar SB, Pressler SJ, Moser D (2016) Depressive symptoms in patients with hearth failure negatively affect familiy caregiver outcomes and quality of life. Eur $\mathrm{J}$ Cardiovasc Nurs 15(1):30-38. https://doi.org/10.1177/1474515114535329

29. Pinto RA, Holanda MA, Medeiros MM, Mota RMS, Pereira EDB (2007) Assessment of the burden of caregivnig for patients with chronic obstructive pulmonary disease. Respir Med 101:2402-2408. https://doi.org/10.1016/j.rmed.2007.06.001

30. Janssen DJ, Engelberg RA, Wouters EF, Schols JMGA (2012) Symptom distress in advanced chronic organ failure: disagreement among patients and family caregivers. J Palliat Med 15:447-456. https://doi.org/10.1089/jpm.2011.0394

31. Snippe E, Maters GA, Wempe JB, Hagedoorn M, Sanderman R (2012) Discrepancies between patients' and parteners' perception of unsupportive behavior in chronic obstructive pulmonary disease. J Fam Psychol 26:464-469. https://doi.org/10.1037/a0028333

32. Krug K, Miksch A, Peters-Klimm F, Engeser P, Szecsenyi J (2016) Correlation between patient quality of life in palliative care and burden of their family caregivers: a prospective observational cohort study. BMC Palliative Care 15:4. https://doi.org/10.1186/s12904-016-0082-y

33. Butow PN, Price MA, Bell ML et al (2014) Caring for women with ovarian cancer in the last yaer of life: a longitudinal study of caregiver quality of life, distress and unmet needs. Gynecol Oncol 132:690-697. https://doi.org/10.1016/j.ygyno.2014.01.002

34. Simpson AC, Yong J, Donahue M, Rocker G (2010) A day at a time: caregiving on the edge in advanced COPD. Int J Chron Obstruct Pulmon Dis 5:141-151. https://doi.org/10.2147/copd.s988

35. Poulin MJ, Brown SL, Ubel PA, Smith DM, Jankovic A, Langa KM (2010) Does a helping hand meant a heavy heart? Helping behaviour and well-being among spouse caregivers. Psychol Aging 25(1):108-117. https://doi.org/10.1037/a0018064

36. Schulz R, Beach RS (1999) Caregiving as a risk factor for mortality: the caregiver health effects study. JAMA 1999 282(23):2215-2219. https://doi.org/10.1001/jama.282.23.2215 
37. Kurtz ME, Given B, Kurtz JC, Given CV (1994) The interaction of age, symptoms and survival status on physical and mental health of patients with cancer and their families. Cancer 74(7suppl):20712078. https://doi.org/10.1002/1097-0142 (19941001)74:7

38. Crouch E, Probst J, Bennett K (2017) Rural-urban differences in unpaid caregivers of adults. Rural Remote Health 17:4351. https://doi.org/10.22605/rrh4351

39. Brodaty H, Donkin M (2009) Family caregivers of people with dementia. Dialogues in Clinical Neuroscinece 11:217-228. https://doi.org/10.31887/dcns.2009.11.2/hbrodaty

40. Lilly MB, Laporte A, Coyte PC (2007) Labor marker work and home care's unpaid caregivers: A systematic review of labor force participation rates, predictors of labor market withdrawal, and hours of work. Milbank Quaterly 85:641-690. https://doi.org/10.1111/j.1468-0009.2007.00504.x

41. Ory MG, Hoffman RR, Yee JL, Tennstedt S, Schulz R (1999) A detailed comparsion between dementia and nondementia caregivers. Gerontologist 39:177-185. https://doi.org/10.1093/geront/39.2.177

42. Liu Y, Dokos M, Fauth EB, Lee YG, Zarit SH (2019) Financial strain, employment, and role captivity and overload over time among dementia family caregivers. Gerontologist 59:e512-e520. https://doi.org/10.1093/geront/gnz099

43. Chou Y-C, Pu C-Y, Kroger T, Fu L (2010) Caring, employment, and quality of life. Comparsion of employed and nonemployed mothers of adults with intellectual disabillity. Am J Intellect Dev Disabill 115(5):406-420. https://doi.org/10.1352/1944-7558-115.5.406

44. Jeyagurunathan A, Sagayadevan V, Abdin E et al (2017) Psychological status and quality of life among primary caregivers of individuals with mental illness: a hospital based study. Health Qual Life Outcomes 15(1):106. https://doi.org/10.1186/s12955-017-0676-y

45. Wood R, Taylor-Stokes G, Lees M (2019) The humanistic burden associated with caring for patients with advanced non-small cell lung cancer (NSCLC) in three European countries - a real-world survey of caregivers. Support Care Cancer 27:1709-1719. https://doi.org/10.1007/s00520-018-4419-3 